\title{
Engineering Design Education: Effect of Mode of Delivery
}

\author{
http://dx.doi.org/10.3991/ijep.v3iS2.2447 \\ K. Khalaf, G.W. Hitt, S. Balawi and M.M. Siddiqi \\ Khalifa University of Science, Technology, and Research, Abu Dhabi, UAE
}

\begin{abstract}
This work reports on the gradual transformation from traditional teaching to student-centered, pure problem-based-learning (PBL) in engineering design education. Three different PBL-based modes of delivery with various degrees of modulation or freedom were used in conjunction with the prescriptive design cycle. The aim is to study the effect of the mode of delivery (PBL at various degrees of integration) on engineering design education and design thinking skills, specifically on the development of expert-like attitudes toward design problem solving.
\end{abstract}

Index Terms—Design Cycle; Design Thinking; Engineering; Design Education; Mode of Delivery; Modulated PBL; PBL

\section{INTRODUCTION}

Design, the creative, iterative and often open-ended process of conceiving and developing components, systems and processes in engineering, is a fundamental pillar of engineering education. According to The Accreditation Board for Engineering and Technology (ABET), the engineering design component of a curriculum must include most of the following features: development of student creativity, use of open-ended problems, development and use of modern design theory and methodology, formulation of design problem statements and specification, consideration of alternative solutions, feasibility considerations, production processes, concurrent engineering design, and detailed system description, in addition to constraints, such as economic factors, safety, reliability, aesthetics, ethics and social impact Fehler! Unbekanntes Schalterargument.. In light of this complex, multifaceted nature inherent to engineering design, it is not surprising for the jury to be still out regarding the main elements required for successful design education, particularly content and delivery.

Though the content of design courses has improved in recent years, it continues to suffer from a clear disconnect with the design thinking and process needed to meet modern world demands [2]. Design thinking, according to Brown [3], is the methodology that involves the full spectrum of innovation activities with human-centered design ethos, and typically integrates three principal phases of inspiration, ideation, and implementation. Successful designers of the $21^{\text {st }}$ century do not merely rely on their technical skills, but rather work to match people's needs with what is technologically feasible within a viable business model and implementable strategy [3]. Unfortunately, research shows that today's average engineering student is not always properly equipped with the necessary skills or practice in design thinking methodology or the ability for the systematic process of inquiry and learning, potentially reducing the opportunity for innovation, productivity, as well as business competitiveness.

Dym et al.[2], (2005) explore the various dimensions of design thinking and design thinking skills and characteristics. These skills include the ability to: view design as an iterative loop of divergent-convergent thinking; see the big picture or systems thinking in design; analyze and address uncertainty; make decisions; function effectively as part of a design team; and develop fluency in the several languages of engineering design (verbal, graphical, etc.).

Apart from content considerations, research also shows that the mode of delivery is critical in effective engineering design education [4]. Unfortunately, few engineering design educators take advantage of the wide spectrum of available pedagogical models and their inherent alignment and hence potential applicability to the design process. Inductive learning methods, such as discovery, inquiry-based, case-based, and problem-based learning (PBL), are student-centered learning techniques in which the students are presented with a challenge (problem, project, case study, etc.) and are systematically guided towards acquiring the knowledge to address that challenge [4],[5].

H.S. Barrows[6], one of the pioneers who developed and implemented problem-based learning in medical education at McMaster University four decades ago, defines PBL as "a learning method based on the principle of using problems as a starting point for the acquisition and integration of new knowledge”. As a form of cognitive apprenticeship, the traditional teacher and student roles change in PBL. The students or "apprentices" are empowered to assume increasing responsibility for their learning. The teacher, on the other hand, assumes the role of a facilitator or "master tradesman" coaching and scaffolding expert problem-solving strategies [7]. The progression of a PBL cycle is typically as follows: (1) student teams are presented with a complex, ill-structured problem. (2) Students define the problem and identify the skills needed to solve it. (3) Students engage in learning first independently and then cooperatively to build their knowledge base. (4) the cycle is repeated until the students arrive at an acceptable solution [5].

The adoption of PBL as a learning pedagogy in engineering education was partly motivated by the $1997 \mathrm{Na}-$ tional Science Foundation (NSF) report, [8], (Systemic Engineering Education Reform: An Action Agenda). The 
report recommended reform in engineering education particularly stressing teamwork, better industrial links, and the interjection of problem/project based learning [8]. In the last decade, various engineering educators reported on the implementation of PBL as a pedagogical model. Marra et al.[9] quantitatively measured the effects of a team-based PBL freshman design course on student intellectual development at Pennsylvania State University using the Perry scheme. The Perry model mainly suggests that the students' cognitive processes develop gradually over time and could be quantified using 9 levels of increasing complexity and maturity of intellectual development. The design experience correlated positively with enhanced student intellectual development. The authors recommended a longitudinal study to shed more light on the quantification of the curricular reform efforts. Dym and Little [10]advocated the use of PBL in their article on engineering design education, labeling it as the currently "most-favored" pedagogical model for teaching engineering design. Based on their literature review, they established that PBL courses (freshman and otherwise) improve retention rates, student satisfaction, diversity, and learning provided they are designed and administered properly. Their article explored a basic framework for ensuring quality control and enhancement in adopting PBL in engineering design education. Litzinger et al.[5] define effective learning practices as those that support the development of expert professional practice. They explore and recommend a list of affective, meta-cognitive, and cognitive instructional practices that create effective learning experiences. Problem-based learning (PBL) is recommended as a learning pedagogy towards developing the necessary analytical and complex problem solving skills needed to tackle multifaceted challenging engineering problems.

While there is a relative consensus regarding the value of using PBL and/or other models of innovative pedagogy in engineering education, the issues of implementation and the degree of transformation from traditional teaching to student-centered learning continue to be quite challenging and less agreed upon [11]. Literature shows that over the past couple of decades, educators have experimented with many varieties of PBL with different degrees of freedom, [12]. In his article regarding the implementation of PBL, De Graaf[11] explores the dilemma of PBL implementation and discusses the advantages and disadvantages of a range of implementation strategies. Kou and Mehta [13] used PBL in an Engineering Measurements course as part of the Mechanical Engineering curriculum at North Dakota State University. Their two year consecutive study used three different teaching methods: (1) traditional; (2) PBL; and (3) combined. Their results showed that the PBL method (used partially or fully) significantly improved analytical and open-ended problem solving skills, cooperative team work skills, as well as written and communication skills. Huang et al.[14] compared traditional instructional modes, such as subject-based learning, cookbook laboratories, and group work, with nontraditional, active engagement pedagogies, such as problem-based learning, project-based learning, cooperative and collaborative learning. They also considered mixed learning methods including subject + project assisted and subject + cooperative learning models. Four main factors were used to evaluate the risks and benefits of a particular learning pedagogy, namely, student factors, instructor factors, course factors, and institution factors. Their results showed that while non-traditional pedagogies have advantages and disadvantages, it is quite beneficial to incorporate active learning components in engineering education. Brodeuret al.[15]reported on PBL experiences in undergraduate aerospace engineering at the Massachusetts Institute of Technology (MIT). They recommended the vertical integration of PBL across all four years to provide a natural progression from structured problems, which require high levels of faculty direction and support, to unconstrained and more complex problems that resemble real life situations. Their results reflected that students at MIT who underwent the regulated mode of PBL reported a greater understanding of core science and engineering courses, found learning more interesting and engaging, and established better connections between their education and real-world applications.

The implementation of PBL as pedagogy in engineering design education has the added advantage of the inherent alignment between the PBL cycle and the prescriptive design cycle. Both cycles start with ill structured, open-ended, complex problems and require following an iterative loop of divergent-convergent processing/decision making to reach an optimal solution. Previous work by the authors [16],[17] reported on the design, implementation, and assessment of a design-and-build course infused at the freshman level. The course integrates the design cycle with a mode of PBL towards the promotion of effective inquiry and the systematic interplay of divergent/convergent design and system thinking/questioning. The impact of the course was assessed using a custommade design survey as well as other measures of adherence to the design cycle. The results showed that the course graduates were significantly more likely to express expert attitudes consistent with professional engineers in terms of problem solving and design thinking as compared to their counterparts who did not take the course. Adherence to the design cycle, as measured by the products at various stages/milestones, also positively correlated with the quality of the finished designs [16],[17].

This paper reports on efforts at Khalifa University for gradual transformation from traditional, instructorcentered lecture-based teaching to student-centered, problem-based learning (PBL) using three pedagogical models based on different integrations of lecture-based and PBL approaches. The main research question that is raised here is whether the mode of delivery has any effect on measures of design thinking in students. How and to what degree does the introduction of PBL into freshman design education enhance design thinking and the proper adherence to the design cycle? Our hypothesis is that positive effects on design thinking will be inversely proportional to the centrality of the lecture component in the course format (i.e. the more central is the lecture component, the less effective will be the course for producing design thinking).

This paper is structured to address these questions as follows: In Section II, we describe the core course content (the design cycle), an important control in this experiment that is held constant across all pedagogical modes, as well 
as the pedagogical modes themselves under study. Section III describes the Engineering Problem Solving Survey (EPSS), our recently developed measure of design thinking in the affective (attitudes) domain and, in Section IV, post instruction scores from this instrument on each of the various student populations. In Section V, we draw conclusions on these results and make recommendations for future research.

\section{The Design Cycle AND Modes of Delivery}

\section{A. The Design Cycle}

Stage I: Problem Definition/framing: student teams are given a "real life" engineering problem using a client statement as a start for the communication. The statement is typically designed to be ill posed and open-ended in nature with real constraints in order to narrow down the options and converge to a solution in a timely fashion. The students are then encouraged to use formal design methods in defining and farming/revising the problem, as used by experts/engineers, such as pruned lists of objectives, objective trees, pair-wise comparison charts, usevalue analysis, etc. The expected outcome of this stage of the cycle is a well-defined problem statement with clear objectives and metrics, and clearly identified design constraints, in alignment and consultation with the client (instructors).

Stage II: Conceptual Design: An iterative divergentconvergent approach [2] is adopted during this stage. Student teams are coached to engage in the various activities involved in the conceptual design process. The process begins with brainstorming, where the students are introduced to and encouraged to use the 6-3-5 and the Csketch techniques, as described by Dym et al.[18]. One of the added values of these techniques is the ability to promote and monitor positive team interaction and group dynamics. The next step in the conceptual design process involves identifying the functions that the design must perform and formulating the design requirements. Formal means such as function-means trees and morphological charts are used to establish the functions and their specs, as well as the means for performing these functions.

The students are encouraged to follow an iterative divergent-convergent process to think out of the box and divergently consider the various design alternatives. They are then coached to systematically refine the design space, keeping in mind the client needs and constraints and the project's viability. Design alternatives are iteratively generated at this stage, quantified with appropriate metrics, and converged towards a final design. The expected outcome of stage II of the cycle is the convergence of each student team on a final design optimally selected based on decision selection matrices from the design space.

Stage III: Preliminary and Detailed Design and Build: based on the conceptual design selection, the student teams model and build the selected design prototype using available tools such as parts, motors, and sensors from their toolkit (Lego Mindstorms), Pro Engineer solid modeling software, as well as, any extra purchased and/or custom-made parts that they prototype as needed using the 3-D printer. They also use NXT++ (the software library integrated with the Lego Mindstorms) and $\mathrm{C}++$ sequential command line programming in order to interface with and control their designs.

Teams go through iterative loops of evaluating/questioning their design before prototyping their solutions. They are coached to use the holistic system-level approach in design assessment and evaluation, and are encouraged to continuously and systematically question their choices. Instructors at this stage act as coaches to help the students in their assessment and inquiry sessions. Microsoft Project is used as a tool in creating and defining timelines and Gantt charts. A leader of a group is expected to manage and follow up on the members' tasks and assignments. The outcome of this stage is a finalized system design, which is tested and evaluated.

Stage IV: Design Communication: throughout the course, student teams use Moodle for group discussions. In these discussions they brainstorm, exchange ideas, post meeting minutes, as well as, CAD drawings and hand sketches as related to their designs. Upon project completion, each team is required to submit a written report that includes all the design details, drawings, figures and tables, and the $\mathrm{C}++$ computer code developed. In addition, each team has to do an oral demonstration/presentation to peers and instructors. During the demonstration, the instructors arbitrarily question each team member to insure individual accountability. Certain projects include a competition among teams in which a winning team is chosen based on peer evaluations. The final project is presented via a formal Power Point presentation, which must include participation from all team members. Each team also generates a final poster reflecting the entire design cycle and fully describing the design process.

\section{B. Modes of Delivery}

\section{Mode I: Synchronous PBL}

In this delivery mode, The Freshman Engineering Design and Build course has two components that are synchronously aligned both in content and phase to effectively deliver the course. This is enabled through a structure of two 1-hour lecture meetings and one 3-hour "lab/studio" meeting per week. In this mode, the lecture aims to theoretically cover the design cycle from problem framing to conceptual design and preliminary design and build, and finally to design communication. The students are lectured on the iterative design cycle, the design process, as well as the various formal design methods and tools such as objective trees, function mean trees, and morphological charts. They are also introduced to team and project management principles and are engaged in analyzing various hypothetical case studies and examples. The lab, on the other hand, relies on PBL as a cognitive form of apprenticeship, where the students receive minimal faculty direction and engage cooperatively in teams to solve open-ended, ill-posed design problems. The problems are introduced in the form of client statements, which they have to reformulate as appropriate and subsequently incorporate into the prescriptive design cycle towards a viable solution. The lectures and the labs are carefully synched together such that each stage in the design cycle along with its outcomes and deliverables is introduced in lecture prior to the associated lab. For example, for stage I, the students are first introduced to the 
concepts of pruned lists of objectives, objective trees, and pair-wise comparison charts in phase with the client statement introduced in the lab and are expected to come up with a well-defined problem statement with clear objectives and metrics, and clearly identified design constraints. Similarly, during stage II or the conceptual design stage, the students are lectured on the iterative convergentdivergent techniques of the design process from brainstorming using the 6-3-5 and C-sketch techniques, to formulating the design requirements using function mean trees and morphological charts. These lectures are synched again both in content and phase with the lab, where the students now take these formal techniques and translate them into their projects, systematically refining the design space within the client's needs and problem constraints.

In order to facilitate the proper alignment and functional synchronization between the lecture and lab, small projects are introduced in the lab for variable durations instead of one big semester-long project. This ensures that the new tools and techniques are introduced and implemented in a timely fashion that properly aligns with the lecture, and also guarantees that the students practice the design cycle multiple times during the semester, which enhances the reinforcement of the design process and most importantly the iterative, divergent-convergent design thinking involved in the process.

Learning outcomes assessment is based on three types of performance assessment: self-assessment, peer assessment, and instructor assessment. In self-assessment, the students mark themselves and their other group members in terms of \% contribution to the group effort. Peer assessment involves the students evaluating other team designs in terms of functionality and creativity on a Likert-scale. Students are also asked to challenge other teams' designs, who in turn are asked to defend their designs. The results of the self and peer evaluations are partly taken into consideration when instructors evaluate team projects. Instructors also follow up on the Moodle discussions when the team is not in the lab. Based on the contributions and the involvement in the team discussions, the highly motivated team members and contributors are rewarded.

In the synchronous mode of delivery, student performance assessment is calibrated depending on the depth of lecture coverage. For example, while each project requires a final demo (presentation + poster), a heavier component of the grade is based on the final project demo since by that time the students would have covered the various stages of the design cycle multiple times during lecture, practiced using the formal design methods repeatedly in the lecture and lab, had many chances to work well as a team and are hence expected to produce better outcomes.

\section{Mode II: Asynchronous PBL}

In this delivery mode, The Freshman Engineering Design and Build course at Khalifa University has two components: two 1-hour lecture meetings and one 3-hour lab meeting each week. In this mode, the lecture component covers the basic principles of the design cycle, team and project management. However, unlike in the case of Mode I, the lecture component is not necessarily synchronized with the lab component, in terms of milestones or alignment between the design projects done in the lab and the design process material covered in the lectures. Students work on ill-posed open-ended projects in the lab without being introduced to all necessary design process topics or formal design methods and tools in the lectures. The main idea behind this mode is to give students the freedom to self-study and loosely apply the design process based on their own interpretation.

The duration of the lab projects and their complexity are scaffolded in a similar manner to Mode I, i.e. the first few projects are of shorter duration and less complexity, whereas subsequent projects are of longer duration and more challenging.

Also similar to Mode I, each project is initiated by a client problem statement that students go over and discuss at the start of a typical lab session. Instructors help clarify any items that may be unclear in the problem statement. Students spend most of the lab time brainstorming and working on projects, in groups of four to five. Instructors evaluate progress by requesting each group to present project updates, and asking questions about methodologies adopted, work breakdown and project milestones. Where appropriate, lab sessions are utilized to introduce students to necessary software programming skills (like $\mathrm{C}++$, Java and MATLAB) and hardware tools needed to perform the project.

Learning outcomes assessment for each project typically consists of two parts: (1) evaluation of the prototype demonstration; (2) evaluation of a formal project report consisting of detailed discussions about the 4-stage design process, the work breakdown structure and project budget estimates. The performance of the prototype is evaluated by the instructors, as well as by all participating students (peer evaluation). In addition, the final project (which is typically a 3-week project) requires project posters to be presented (showing details of the system design), as well as formal project update PowerPoint presentations (for each student group). For projects that involve programming, the prototype demonstration also includes weighting for code optimization and efficiency.

\section{Mode III: Pure PBL}

In this mode of delivery, the Freshman Engineering Design course at Khalifa University has only one component; the design studio which meets twice weekly for three hours each meeting. The key features of the Pure PBL modality used here are; (1) the lack of a didactic lecture component to the course (the instructor is a mere facilitator or coach and the students are fully in charge of their own learning) (2) the use of three, multi-week, projects to facilitate experiential learning of all course content, (3) classroom norms consistent with the divestment of the course instructors as purveyors of knowledge, and (4) assessment of student learning largely through live, inclass prototype demonstration performances.

All contact time for the course takes place in a large design studio containing team-dedicated cubicles with large, round tables, bulletin and white boards, all organized around the perimeter of the room, a large, central workbench enabling fabrication work, and an adjacently 
located stock room for raw materials. The geometry of the design studio is shown below in Figure (1) and is intended to communicate to students that it is their teams and their design work that are of central importance in the course, not the instructor or what is displayed at the front of the room.

In the Pure PBL modality, student learning for course content is enabled through three, multi-week projects, ranging from 3 to 8 weeks in duration each.

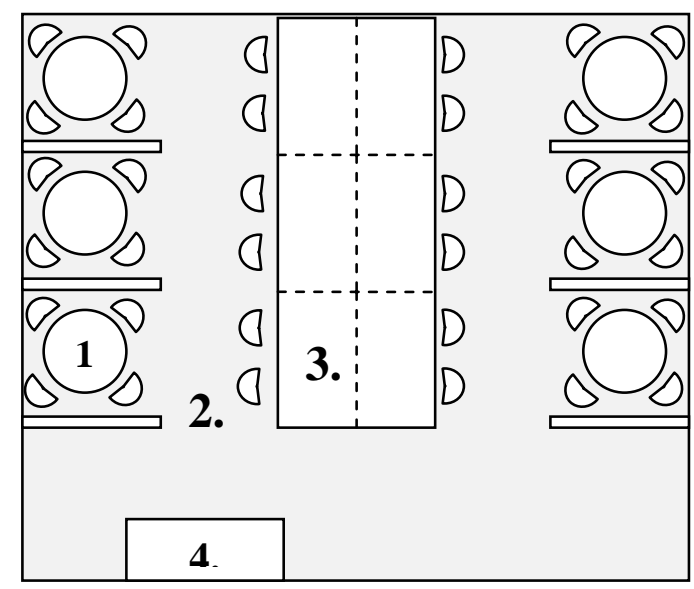

Figure 1. Classroom geometry of the design studio for the Freshman Engineering Design Course, using the Pure PBL pedagogical model, containing (1.) workspaces with round tables, chairs, bulletin boards and white board walls, (2.) partial partition walls, (3.) partitioned workbenches, and (4.) and instructor's island.

All three projects are initiated by a brief client problem statement, written so as to cast the project as an illposed, open-ended, realistic problem to be solved with a designed solution. Instruction comes in the form of a cognitive apprenticeship [19] with the usual phases of modeling, coaching/scaffolding, and fading, all taking place in a workshop-style pacing. Instructors spend 5-10 minutes modeling a part or all of the tasks in the design cycle presented above using an example client problem. Next, instructors release teams for 10-30 minutes to repeat the same task on the example problem and periodically visit teams to ask questions and challenge assumptions. Last, teams must abstract upon and extrapolate lessons learned from these activities and apply them to solve the client problem presented in their current project. Modeling and coaching phases vary significantly in level, duration and frequency, but in general, they are longest and most frequent during the first project in the course and are gradually weaned over the three-project sequence. There is essentially no classroom time spent on modeling conceptual design tasks during the third and final project. During the midst of the second and third projects in the course, much of the 3-hour classroom time is completely unstructured.

Learning outcomes for projects are assessed through a combination of written report, oral presentation and a live, metric-based prototype demonstration performance.

\section{A MEASURE FOR DESIGN THINKING}

One of the key metrics used in this study, as a measure of design thinking in students, is their response on the
Engineering Problem Solving Survey (EPSS). These authors have reported elsewhere the motivation for developing the survey instrument and the philosophy adopted in its construction [20], the evidence of its criterion validity, as judged by expert engineer responses, and its internal reliability [16], and the evidence of its construct validity due to its scores' strong-to-moderate positive correlation with measures of students' live design demonstration performances [17].

To briefly summarize these references, the EPSS is a survey instrument generally designed to measure in the affective domain and specifically designed to measure the favorability of student attitudes toward the design problem solving process. The survey is inspired by similar attitudinal instruments developed through physics education research (e.g. Maryland Physics Expectations Survey by Reddish, Saul \& Steinberg 1998[21]) and takes the same form, that of a set of statements to which students are asked to respond in agreement or disagreement on a 5point Likert scale. A survey instrument of this kind for measuring design thinking is attractive for several reasons; (1) it does not require calculation or deep conceptual understanding of technical content, so it can be given to entering freshman, the core audience of a freshman design experience, (2) in physics education research, students' favorable/expert-like attitudes toward the learning process associated with forthcoming physics content have been shown to be positively correlated and causally connected with measures of student learning gains [22], and (3) there are good reasons to expect a similar connection between expert-like attitudes toward the design process and student learning about design [17]. To aid the reader, some example statements from the survey read, "To solve any design problem, I only need to figure out what kind of problem it is and look up the solution in a textbook or journal article", and "I avoid building rough prototypes and focus on building the final design solution.” In these two examples, the response considered favorable by these authors' would be to 'strongly disagree'. As reported by these authors [20], this is the consensus of $100 \%$ of professional engineers surveyed to date. In total, the survey contains 8 such statements.

For each of the pedagogical modes described in Section II, the EPSS was administered as a post-instruction measure. Responses on each item were categorized by the authors as either "favorable", "unfavorable" or "neutral". The percent favorable score is taken as a measure of design thinking in the respondent in general and in specific, as a measure of the degree to which the respondent sanctions the design behavior or design belief described by the survey statements.

\section{RESULTS AND DisCUSSION}

Table (1) shows descriptive statistics for each of the populations sampled with the EPSS. Two populations' responses to the survey, a simulated random response and responses of professional engineers, are used in benchmarking the comparison between the different pedagogical modes.

On one end of the metric is a random population which is not a real population at all, but rather, it is a simulated random response to the survey. Each survey 
item is a 5-point Likert scale response and the analysis declares a response favorable in 2 out of the 5 possible responses for any given item (i.e. if the authors would "strongly disagree" to a given statement, the respondent's response is considered "favorable" if they also "strongly disagree" or "disagree"). Therefore, we assume random responses should be binomially distributed with $p=2 / 5=$ 0.4 and $n=8$. As a consequence, the distribution expected is reasonably normal and the standard deviation is approximately $\sigma \sim(p(1-p) / n)^{1 / 2}=17 \%$. For $N=30$ random respondents, this gives a standard error in the mean of $3 \%$. Numerical simulation confirms this. At the other end of the metric are $N=25$ practicing engineers, surveyed as part of the development of the EPSS[16].

TABLE I.

POPULATION SIZES AND SCORES ON THE ENGINEERING PROBLEM SOLVING SURVEY. ERRORS REPORTED ARE STANDARD ERRORS IN THE $\operatorname{MEAN}(\sigma / \sqrt{ } \mathrm{N})$

\begin{tabular}{clc}
\hline Population & Size $(N)$ & $S \pm$ s.e.(\%) \\
\hline \hline Random Response & $N=30$ & $40 \pm 3$ \\
Lecture & $N=124$ & $43 \pm 3$ \\
Synchronous PBL & $N=34$ & $63 \pm 4$ \\
Asynchronous PBL & $N=30$ & $53 \pm 6$ \\
Pure PBL (prelim.) & $N=123$ & $60 \pm 3$ \\
Professional Engineers & $N=25$ & $84 \pm 2$ \\
\hline
\end{tabular}

Figure (2) shows the survey scores with errors for all the populations considered, including the two benchmark populations bracketing the set. There are several noteworthy observations to be made. First, it is clear that regardless of pedagogical mode, courses that have incorporated a PBL component in some fashion produce more expertlike attitudes toward design problem solving in their students. The average score post-instruction over all PBL modes is $59 \pm 3 \%$ and is significantly greater than $43 \pm 3 \%$ of lecture-based instruction. The population sizes for these data are too small to reliably determine if they are normally distributed. Therefore, to estimate the level of significance, the nonparametric Wilcoxon or Mann-Whitney rank sum test [23] was performed on the two sets (All PBL vs. Lecture), giving a test statistic of $Z=5.04$ and an associated two-tailed $\mathrm{p}$-value of $p<0.001$. Thus, we can reject the null hypothesis (that lecture is similar or better than PBL for producing favorable design problem solving attitudes in students) with greater than $99.9 \%$ confidence. Design studios, implemented in any way with regards to a lecture component, improve the positive attitudinal shifts of students by $+16 \%$ over lecture alone and $+19 \%$ over random response and both differences are very significant.

Another important observation is the poor performance of lecture-only instruction. At $43 \pm 3 \%$, the lectureonly mode does not produce scores on the EPSS that are significantly different from $40 \pm 3 \%$ for random responses. Furthermore, the effects of combining a lecture component with a PBL component (such as design studios in this work) can be estimated, either by calculating the difference for removing the lecture from the Synchronous $\left(S_{\text {Pure }}\right.$ $-S_{\text {synch. }}$ ) or Asynchronous modes $\left(S_{\text {Pure }}-S_{\text {asynch. }}\right)$, leaving only Pure PBL. The results, like that of the lecture over random response, are consistent with zero, suggesting that adding a lecture to an existing Pure PBL course has a negligible impact on effecting positive attitudinal development in students.

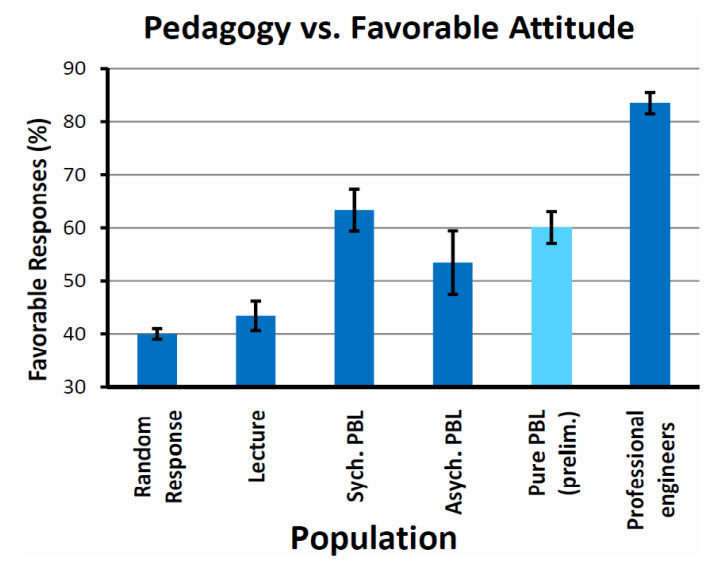

Figure 2. Bar chart representation of average scores from the Engineering Problem Solving Survey.

Of course, this result for lecture instruction by itself does not mean such instruction produces no learning, as the survey measures only in the affective and not in the content domain. Students may certainly learn a lot about the design process and design problem solving in the form of facts. Nevertheless, it is discouraging to realize that, following 16 weeks of lecture-based instruction, there is no discernible movement in the mean. Consider also individual survey statements, like the examples mentioned above; "I avoid building rough prototypes and focus on building the final design solution." and "To solve any design problem, I only need to figure out what kind of problem it is and look up the solution in a textbook or journal article”. To the first statement, 65\% of lectureinstructed students either agreed to the statement or had no opinion, implying that they do not clearly see the need to build prototypes. It is equally discouraging, though not surprising, that $63 \%$ of respondents agreed or had no opinion about the second statement, suggesting that many suspect that any design problem could be solved by looking up the solution in a book or journal article. Surely, this is not a desirable effect for any kind of design education but it seems consistent with a mode of instruction that is mainly driven by case studies and book-reading.

Comparing the three PBL modalities, at this time it is difficult to draw strong conclusions about their relative efficacy. The largest difference is between Synchronous PBL and Asynchronous PBL, with the synchronously instructed students scoring 10\% more favorably. However, the rank sum $Z$-statistic associated with comparing these two mean scores is $Z=1.15$ which has a corresponding two-tailed $p$-value of $p \sim 0.25$, so the null hypothesis (that Synchronous and Asynchronous PBL mean scores are the same) cannot be confidently rejected. For Pure PBL, it is worth mentioning however, that the Pure $P B L$ data is preliminary, taken mid-semester, as part of regular monitoring for the course which is in its pilot implementation at the time of this article's writing. Given the increase in favorable responses over the random response, seen in the other two PBL modes, it is reasonable to expect that when post-instruction data is take for the Pure PBL group, the mean score on the survey will be equal or higher. 


\section{CONCLUSIONS AND FUTURE WORK}

This paper presents ongoing work to study the impact of gradual transformation from didactic, lecture-based traditional teaching to student-centered, studio-based, PBL in freshman engineering design education. Towards this goal, three different PBL modes used for imparting a working knowledge of a four-stage, prescriptive design cycle were examined. The effects of these modes on the development expert-like attitudes toward design problemsolving were measured using EPSS and benchmarked against random response, lecture-only instruction and professional engineers' responses.

The results of this work clearly show that PBL in general, regardless of its mode of delivery, substantially improves students' favorable attitudes towards design problem-solving. Our hypothesis, that courses in which a PBL component is incorporated in some fashion significantly produce more expert-like attitudes toward design thinking and problem solving in the students, as compared to lecture-based instruction, is supported. In agreement with literature, our results also showed that design studios, implemented in any way with respect to a lecture component, significantly improve the positive attitudinal shifts of students over lecture alone. On the other hand, for an existing PBL course, adding a lecture component, regardless of its modality, has a negligible impact on effecting positive attitudinal shifts in students. This agrees with the common theory that the development of expert-like thinking in young students is best effected by cognitive apprenticeship in a community of practice [19] that is kinesthetically engaging (hands-on), experiences that any lecture format is hard-pressed to provide.

Contrary to the case of lecture instruction, differences between PBL modes were not as pronounced as expected. The difference seen between Synchronous PBL and Asynchronous PBL, while large and opposite to what was expected, is also not statistically significant. Similarly, Pure PBL taught students have not scored as high on EPSS as anticipated. This may be partly explained by the fact that the Pure PBL class is in progress and the data is preliminary (taken mid-semester, rather than postinstruction). Thus, post-instruction results for Pure PBL may yet reveal the superiority of this approach, but more data from asynchronously delivered courses will also likely be needed to establish the statistical significance of any differences seen.

Work is ongoing to further refine the EPSS or a future survey instrument for measuring design thinking. This and previous work ([16],[17],[20]) have focused solely on measures in the affective domain, of student attitudes toward design problem solving. This alone should not be the sole, or even the most important measure of instructional value. Measures of design thinking in the cognitive domain (e.g. of the decision-making processes that students go through during design) and the effective domain (i.e. the quality of student prototypes, as measured by their projects' metrics and constraints) must be added to and correlated with measures presented in this work, before a complete picture of the performance of PBL vs. lecture or hybrid approaches will be clear.

\section{REFERENCES}

[1] The Accreditation Board for Engineeirng and Technology (ABET). Engineeirng Criteria 2000, $3^{\text {rd }}$ ed, December 1997.

[2] Dym,C. L., Agogino,A.M., Eris,O., Frey,D., and Leifer,L.J., "Engineering, design thinking, teaching, and learning," Journal of Enginereing Education, vol. 94, pp. 103-120, 2005.

[3] Brown,T., "Design thinking," Harvard Business Review, pp. 8494, June 2008.

[4] Prince,M., and Felder,R., "The many faces of inductive teaching and learning,” Journal of College Scinece and Teaching, vol. 36, pp. 14-20, April 2007.

[5] Litzinger,T.A., Lattuca,L.R., Hadgraft,R.G., and Newstetter,W.C., "Engineering Education and the Development of Expertise," Journal of Enginereing Education, vol. 100, pp. 123-150, 2011.

[6] Barrows, H.S., "The essentials of problem-based learning", Journal of Dental Education, Vol. 62, No. 9, 1998, pp. 630-633.

[7] Newstetter, W., "Fostering Integrative Problem Solving in Biomedical Engineering: The PBL Approach", Annals of Biomedical Engineering, Vol. 34, No. 2, 2006, pp. 217-225. http://dx.doi.org/10.1007/s10439-005-9034-z

[8] National Science Foundation, http://www1.needs.org/coalitions/ info/descripotion.html.

[9] Marra, R.M., Palmer, B., and Litzinger, T.A., "The Effects of a First-Year Engineering Design Course on Student Intellectual Development as Measured by the Perry Scheme”, Journal of Engineering Education, Vol. 74, No.1, 2000, pp.39-45. http://dx.doi.org/10.1002/j.2168-9830.2000.tb00492.x

[10] Dym, C.L, Agogino, A.M., Eris, O., Frey, D.D., and Leifer, L.J., " Engineering Design Thinking, Teaching, and Learning", Journal of Engineering Eduction, vol. 94, No. 1, p103-120, 2005

[11] De Graaff, E.D., Implementation of PBL: piecemeal or all the way? International Journal of Engineering Education, vol 101, pp. 124-148, 2011.

[12] PBL Network, http://pbln.imsa.edu/network/sitemap.html.

[13] Kou, Z., and Mehta, S., "Lessons Learned from Incorporating Problem-Based Learning and Lego System in Engineering Measurements Laboratory" Proceedings of the 2005 American Society for Engineering Education Annual Conference \& Exposition, Portland, Oregon, 2005.

[14] Huang, M., Malicky, D., and Lord, S., "Choosing and Optimal Pedagogy: A Design Approach”, Proceedings of the $36^{\text {th }}$ ASEE/IEEE Frontiers in Education Conference, San Diego, CA, 2006.

[15] Brodeur, D.R., Young, P.W., and Blair, K.B., "Problem-Based Learning in Aerospace Engineering Education”, Proceedings of the 2002 American Society for Engineering Education Annual Conference \& Exposition, Montréal, Quebec, Canada, 2002.

[16] Khalaf, K., Balawi, S., Hitt, G.W., and Radaideh, A. Engineering Design Education: Towards Design Thinking. ICL/Educon 2012, Austria, September 2012

[17] Khalaf K., Balawi, S., and Hitt, G. (2012). Engineering Design Education, When, What, and How. American Engineering Education.In Review.

[18] Dym, C.L., and Little, L.,” Engineering Design: A Project Based Introduction”, $3^{\text {rd }}$ ed,New York, John Wiley \& Sons. 2009

[19] Brown, J. S., Collins, A., \& Duguid, P. (1989). Situated cognition and the culture of learning. Educational Researcher, 18, 32-42.

[20] Khalaf,K., Balawi,S., Hitt,G.W., and Radaideh,A., "Innovation in teaching freshman engineering design: an integrated approach ," In Proceedings of EDULEARN, Barcelona, Spain, pp 216-222, 2010.

[21] Redish, E, j.m. Saul, and R.N. Steinberg, "Student Expectations in Introductory Physics”, American Journal of Physics, Vol. 66, pp.212-224, 1998. http://dx.doi.org/10.1119/1.18847

[22] Adams,W.K., Perkins,K.K., $\quad$ Podolefsky,N.S., Dubson,M., Finkelstein,N.D.,. Wieman,C.E, "New Instrument for Measuring Student Beliefs about Physics and Learning Physics: The Colorado Learning Attitudes about Science Survey”, Physical Review Special Topics - Physics Education Research, Vol. 2, No. 010101, 2006.

[23] Hollander, M. and Wolfe, D. A., Nonparametric Statistical Methods, 2nd ed., Wiley Interscience, New York, 1999. 


\section{AUTHORS}

K. Khalaf is with Biomedical Engineering Department, Khalifa University of Science, Technology, and Research, Abu Dhabi, UAE. (e-mail: kinda.khalaf@kustar.ac.ae).

G.W. Hitt is with the Department of Applied Mathematics and Sciences at Khalifa University of Science, Technology, and Research, Abu Dhabi, UAE. (e-mail: george.hitt@kustar.ac.ae).

S. Balawi is with the Aerospace Engineering Department, Khalifa University of Science, Technology, and
Research, Abu Dhabi, UAE. (e-mail: shadi.balawi@kustar.ac.ae ).

M.M. Siddiqi is with the Aerospace Engineering Department, Khalifa University of Science, Technology, and Research, Abu Dhabi, UAE. (e-mail: mohammad.siddiqi@kustar.ac.ae ).

This article is an extended and modified version of a paper presented at the International Conference on Engineering Pedagogy (IGIP2012), held 26 - 28 September 2012, in Villach, Austria. Received 15 December 2012. Published as resubmitted by the authors 27 February 2013. 